\title{
LAS "ANIMITAS": TESTIMONIO RELIGIOSO E HISTÓRICO DE PIEDAD POPULAR EN CHILE
}

\author{
Antonia Benavente ${ }^{1}$
}

\section{* Introducción}

\section{Resumen}

La configuración de una obra, cualquiera que ésta sea, es una imagen fiel de la sociedad y del tiempo histórico en la cual se inserta. Las imágenes, mobiliarios y objetos, diversos en cuanto a su ornamentación pero integrados en su función, gravitan en torno a la figura, el relato y la estructura que se sitúa como elemento central de la obra. Desde esta perspectiva la "animita" es una obra dedicada al difunto, cuya función se relaciona con la memoria, con el recuerdo de un ser querido, que tiene un comienzo -el momento de su construcción- pero que no tiene término histórico preciso, ya que permanece, está ahí en el lugar del suceso

transformándose en memoria de manera recurrente. En este trabajo intentaremos individualizar y caracterizar esta obra tan particular que permanece en el espacio, dando cuenta de un contexto social que se expresa simbólicamente mediante un conjunto de objetos significativos.

Palabras claves: "animita" - religiosidad popular - recuerdo - memoria.

Abstract

The composition of any artistic work is a faithful representation of the historic period and society in which it is inserted. The ornamentation of the images, furniture and various objects, although integrated to their function, gravitate around their figure, speech, and the structure that is situated as the central element of the artistic work. From this point of view, the animita is a work dedicated to whom is dead, being it's function related to memory, with the remembrance of a loved one; it has a beginning, which is the time of its building, but it doesn't have a precise historical ending, because it lasts, it is located in the place where the event took place, and it transforms in a recurrent memory. In this article we try to define and characterize this type of construction that stays in place speaking about a social context which symbolically express itself through a group of significant objects.

Key words: animita - popular religiosity - remembrance - memory. Recibido: noviembre 2010. Aceptado: abril 2011.

\footnotetext{
1 Depto. de Antropología, Universidad de Chile. Ignacio Carrera Pinto 1045, Ñuñoa, Santiago, CHILE. Email: antoniabenavente@hotmail.com.
}

Cuando hablamos de "animitas", hablamos de religiosidad popular, de la memoria del pueblo, de historias de difuntos, aparecidos, de milagros y de agradecimientos. Las "animitas" que vemos en las carreteras, calles, vías, recodos, desiertos, son el monumento que exige "arraigo" en las comunidades y cumplen la función de recordar la memoria de alguna persona que ha encontrado la muerte en trágicas y desgraciadas circunstancias.

En Chile, este culto se expresa en todo el territorio, plasmándose en cada lugar con características propias de la cultura local, especialmente en lo relacionado con la arquitectura de la "animita"; es decir, con el monumento físico que se alza como contenedor de los registros asociados, muchas veces inexplicables si no se presta atención a la tradición oral que necesariamente la acompaña (Figura 1).

Formalmente, las constituyen pequeñas casitas construidas cerca del lugar de la tragedia que le ocurrió a un peatón, conductor o pasajero de un vehículo. Estas son las "animitas" que se han convertido en entidades persistentes para la comunidad y que, pese al paso del tiempo, se siguen erigiendo en diversos puntos. La creencia popular señala que las almas permanecen en la tierra para honrar a los difuntos que se han ido trágicamente; también asegura que sus almas permanecen en la tierra para borrar sus pecados y que, a cambio de rezos, ayudan a los vivos. Esas creencias sustentan la veneración permanente que se tiene a estas pequeñas casitas denominadas "animitas", de presencia ineludible en el paisaje, albergue de fotografías, flores y ornamentos. Conforman una pequeña posada que se transforma en un santuario 


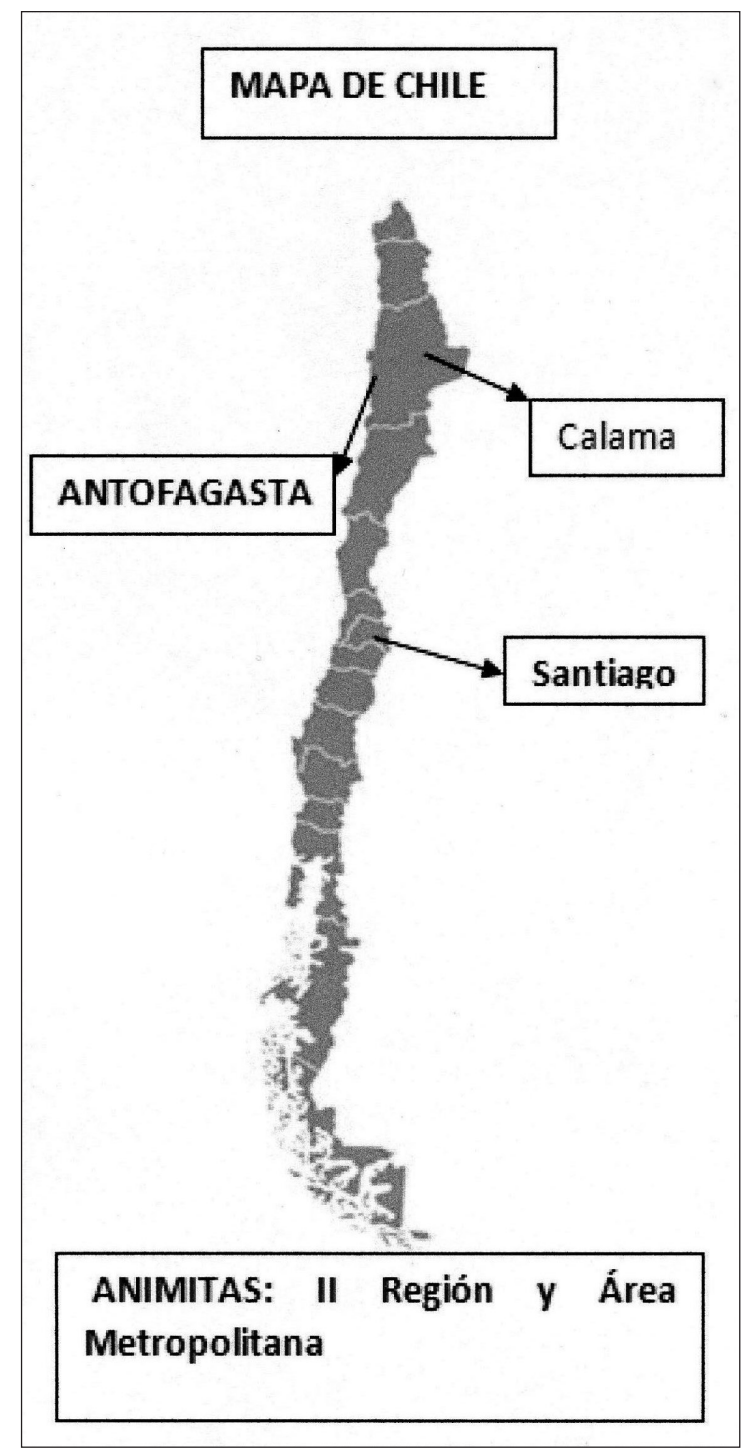

Figura 1. Mapa de Chile que indica la región de Antofagasta, donde se ubican las "animitas" que se mencionan más adelante.

religioso en la medida en que son engalanadas de modo permanente con diversos tributos, regalos o pagos por los favores concedidos a los devotos. Son la arquitectura viviente, mausoleo mínimo sin cadáver que se le construye al difunto, persona casi siempre anónima y otras veces identificable. Las "animitas" tienden al anonimato, sin embargo; es decir, al igual que su figura imperceptible para la gran mayoría, su historia pronto es olvidada y su persistencia en la memoria queda entregada a lugareños y familiares, devotos de un espacio que ha sido creado para ser sagrado y permanecer como tal, en la medida que sean los otros los que le den significación al lugar. El personaje que se quiere recordar es el elemento principal de la estructura, el que define y caracteriza a la "animita", ya que es a éste a quien se dedica la obra. Por lo tanto, la causa de su origen, el espacio que ocupará, los objetos que la acompañarán son únicos, definidos por aquellos que organizan y le dan identidad a la estructura. Ésta mantiene una relación afectiva entre el sujeto y los objetos que caracterizan y particularizan el espacio ocupado por esta forma constructiva y estética, edificada para mantener el recuerdo del difunto. Tal parafernalia ha sido seleccionada y dispuesta por los que quedan, por los que lo recuerdan, lo mantienen en la memoria y lo hacen parte del espacio ciudadano a tal punto que una parte de la sociedad lo considera como uno más de los suyos. Sin embargo, esta parafernalia particular y específica atiborrada de objetos que si bien le dan sentido, muchas veces resulta difícil de dilucidar e interpretar:

"Tienen tan poca autonomía en este espacio como los diversos miembros de la familia tienen en la sociedad. Además, seres y objetos están ligados, y los objetos cobran en esta complicidad una densidad, un valor afectivo que se ha convenido en llamar'su presencia"' (Baudrillard 2007: 14).

En esta ocasión, nos interesa individualizarlas y caracterizarlas. Son especiales, ya que dan cuenta de lo que el sujeto fue en vida, y a través de ellos queremos recordarlo. Estructuradas y construidas para evocar a un individuo que sufrió una muerte inesperada, violenta, muchas veces en solitario, pero de quien alguien conocido o desconocido quiso dejar un testimonio en el lugar de su partida, el que permanecerá para siempre.

Desde esta perspectiva, memoria e identidad emergerán como conceptos relacionados actuando como vínculos para mantener la tradición de la sociedad. La memoria a través del recuerdo y la identidad mediante la atribución de signos adquieren una connotación simbólica en el tiempo histórico en que se ubica la obra. Ambos conceptos pertenecen a la cultura y a la tradición de determinadas comunidades y se expresan simbólicamente, traspasándose al ámbito de la funebria.

Por lo tanto, las "animitas" expresan su identidad a través del nombre del difunto donde su memoria es evoca- 
da mediante algunas lecturas alusivas al momento de la muerte, además de diversos ornamentos con que son adornadas. Encontramos "animitas" adosadas a murallas, calles, caminos, rutas que recorren y caracterizan diversos lugares señalando los momentos de laicización de nuestra historia, la opulencia de algunos y el olvido de otros; pero que a fin de cuentas son parte de nuestra identidad y, por tanto, de nuestra memoria. Su trascendencia y reconocimiento se activa principalmente a través de los núcleos familiares que son sus fieles permanentes, ya que la mayoría va a visitarlas por una costumbre familiar, a pagar una "manda" o favor concedido, así como también a pedir por una "protección" para sus vidas.

En definitiva, la transformación popular de aquellos que han fallecido casualmente -muchos anónimamente-en santos, es otorgada por sus fieles anónimos; y es un culto soterrado, de devotos que no saben mucho de la historia del individuo que se ha ido, y que a lo largo del tiempo pasa a ser un reconocimiento íntimo que nace de una creencia colectiva, que alcanza trascendencia popular.

Como fenómeno universal, la preocupación por las "animitas" forma parte de la cultura chilena. Desde tiempos inmemorables la muerte ha constituido una instancia sagrada, donde no solo el cadáver era agasajado y enterrado junto a sus pertenencias, sino que también han sido ritualizados los espacios que lo recuerdan.

Guardando las proporciones, en el ámbito rural la muerte también ha sido celebrada con una serie de actos sagrados, que van desde los míticos "angelitos" (velorios de niños) hasta las fiestas llenas de pompa y "comilonas" en honor del difunto que duran varios días; así como también dándole a aquellos lugares en que ha ocurrido una muerte trágica una connotación especial al construir una obra -la "animita"- en memoria del muerto.

En esas circunstancias, la muerte adapta las características del trance físico al espiritual; siendo vital la suerte del alma, pues el cuerpo ha quedado depositado en el cementerio bajo los designios de la Iglesia y de las leyes.

Desde un punto de vista teórico, la expresión de la muerte en las "animitas" reúne un conjunto de características que transforman el lugar en que éstas se localizan en un objeto ritual complejo, muchas veces difícil de compren- der y, en consecuencia, de interpretar; no en su función, la que es clara, sino en la forma en que éstas, mediante diferentes diseños entregan al público diversos sentimientos. Dan cuenta de la individualidad del sujeto al insertarse en ellas fotografías del difunto, de niños o de adultos, estampitas, juguetes, banderas o también figuras angélicas. En este último caso, parece ser que es el arcángel Gabriel quien cumple la función de guardián de los individuos en la vida y en la muerte. Asimismo pueden verse diversas figuras religiosas, entre las que se cuentan algunas conocidas y populares que posiblemente resguardaron al individuo en vida y seguirán protegiéndolo para siempre. Todos son recuerdos que acompañaran al difunto en su descanso eterno.

Pensamos que las "animitas" son parte de un sistema simbólico, de diseño estructurado, configurando un conjunto de formas que devienen en signos repetitivos, rasgo indispensable para ser conocidas como parte de los rituales religiosos donde la imagen de los individuos respecto de la muerte viene en paquetes con temáticas seriadas que han sido impuestas por la sociedad. Éstas se construyen en algunas ocasiones en el momento de la muerte, sin mayor elección temática, quizá a causa de la falta de conocimiento, de la imposición del dinero, o del contexto social y religioso del difunto. Las "animitas" también son producto de un diseño que se estructura de manera popular y espontánea, donde toda la comunidad coopera de alguna forma para perpetuar al difunto en la memoria de la comunidad. Ésta, a su vez otorga a las "animitas" una identidad muy particular entre el conjunto citadino que las circundan, siempre destacándolas dentro del conjunto, ya sea urbano o rural.

Las "animitas" componen un sistema integrado por un conjunto de artefactos materiales como flores, fotos, cruces o tarjetas que arropan esta pequeña construcción que alberga el recuerdo de un difunto. Se convierten, por tanto, en artefactos ideales que se expresan en lecturas y epitafios alusivos al muerto. Son signos, que al estar circunscritos en un espacio ritual dan cuenta de la dualidad existente entre la vida y la muerte, siendo connotativos y, como ya señalamos, conforman un sistema simbólico.

Estas formas artefactuales varían en su organización, asumen roles diferentes por los desiguales diseños que las formas constructivas ostentan y que cada una de ellas 
enuncia. Esta característica de las "animitas" de constituir formas constructivas diversas e irrepetibles, en cada lugar en que se localizan, por los artefactos que les son propios además de su forma, permite una estrecha comunicación entre las creencias individuales y privadas atribuidas a cada difunto con la comunidad que acoge la obra.

En este sentido podemos señalar que la concepción respecto de la muerte transita desde un hecho sagrado a un sentido más humanista y social producto de una actitud más racional. Al construirse una obra especial para recordar al difunto fuera del cementerio, se instaura una conceptualización más moderna, de individualización y personalización de la muerte; lo que se traduce a su vez en la emergencia de un nuevo aspecto, cuál es el interés personal o colectivo por mantener dichos espacios con fines rituales, ya que allí son comunes las rogativas y solicitudes con diversos propósitos. Estas rogativas no tienen una relación directa con plegarias a santos, a la Virgen María u otras divinidades, sino que más bien se vinculan con solicitudes practicas y hasta mundanas, como por ejemplo, la preocupación por las herencias y herederos por sobre aspectos desproporcionados e improductivos como podrían ser el bienestar del alma.

Esta es una actitud más racional, pero que tiene mucho del sentimiento personal, ya que es en estos espacios donde los individuos vuelcan su sentir y ponen toda su fe en la búsqueda de lo que se necesita en un determinado momento. Este sentido se transforma en tradición, la que vemos expresada materialmente en estas pequeñas capillitas a veces con cientos de placas recordatorias que agradecen al difunto por los favores concedidos.

Ariés (1983) señala que la muerte produce un sentimiento ineludible que no puede ser ignorado por los individuos, que hace intolerable la muerte "del otro". Así, las personas expresan su sentimiento acerca de la muerte de modo indirecto, no por medio de la verbalización sino que a través de la ornamentación de las construcciones con objetos depositados en lugares que albergan a las ánimas, como tumbas, nichos y lápidas, con el fin no solo de otorgarle una indudable identidad a cada una de ellas, sino también de mantenerlas en la memoria de la sociedad. Este es una manera de perpetuar el recuerdo del difunto como respuesta a esta dificultad de aceptar el dolor que significa este rito de pasaje, haciendo que la persona vuelque su sentimiento de dolor en un artefacto material específico que da sentido parafernálico a una simple fórmula constructiva como es la "animita".

\section{* AnÁlisis}

Las "animitas" nacen de la misericordia de los individuos y comunidades en el lugar donde aconteció una "mala muerte". Se pueden definir como un cenotafio popular, ya que los restos de los que perecieron de manera trágica descansan en el cementerio, por lo que en este otro espacio, se honra el alma del "ánima".

El lugar en el cual finalizó la jornada terrenal de una persona es el mismo donde se construye una pequeña casita, que puede llamarse casilla, templete, ermita o gruta. Son reproducciones o imitaciones de casas -algunas podrán semejar iglesias-, para guarecer al ánima de las inclemencias del tiempo, del calor, del viento, o de la lluvia y por qué no decirlo, también de las personas. Lo usual es que llevan cruces y en su interior y exterior se encienden velas. Las "animitas" se encuentran en las grandes ciudades, en las calles, a la vera de las aceras, en los pueblos, en los extramuros, los caminos...

Hemos señalado que se definen y caracterizan por:

"[...] un mobiliario [...] que es una imagen fiel de las estructuras familiares y sociales de una época [...]. Los muebles, diversos en cuanto a su función, pero ampliamente integrados, gravitan en torno al aparador del comedor o la cama colocada en el medio. Hay tendencia a la acumulación y a la ocupación del espacio, a su cierre. Disfuncionalidad, inamovilidad, presencia imponente y etiqueta jerárquica. Cada habitación tiene un destino estricto, que corresponde a las diversas funciones de la célula familiar, y nos remite, más allá, a una concepción de la persona en la que se la ve como un conjunto equilibrado de distintas facultades" (Baudrillard 2007: 13).

Con lo anterior queremos decir que todo lo que conforma y caracteriza a las "animitas" está definido por quienes seleccionan los "muebles" y ornamentos y decoran la construcción, ilusión de una casa mortuoria que acompañará al difunto para siempre. El espacio central de esta construcción es la "cama central", y la estructura formal con sus particulares diseños es la que albergará, transmi- 


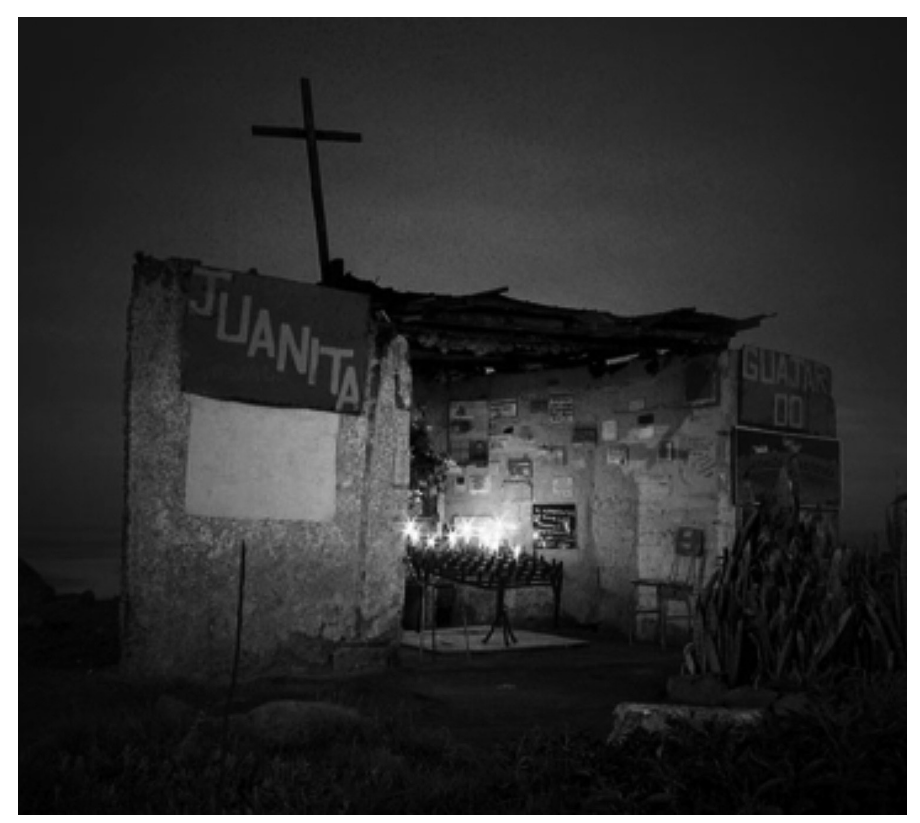

Figura 2. "Animita" de Juanita Guajardo Burgos, Antofagasta. Fotografía de Juan Forch.

tirá y expresará no solo el sentimiento de pérdida de los deudos, sino que mantendrá al difunto en la memoria de la sociedad.

La "animita" que muestra la Figura 2, corresponde a la de la difunta Juanita Guajardo Burgos, y en su interior se lee:

"Nada que le hiciera eco a su antigua belleza

Amarizó así en estas costas de la Avenida Pérez Zujovic 'La Fondeada'

Fue el zapatito de oro colgando del cuello el que delató su cuerpo de sirena abandonada

Ella era Juanita, la peluquera, la bailarina,

Sandra Le Roi para los amigos de la boîte

Era el 21 de febrero de 1983".

Es el deseo de inmortalidad,

"[...] en alounos casos la intención es proteger al difunto en su existencia futura, para que ningún bien le falte; o si la 'vanidad' del difunto y de sus deudos debe ser contemplada por toda la sociedad ad eternum. Es el rol que la persona cumplió en vida y de un modo u otro sigue cumpliendo, al situarse el espacio fúnebre en un lugar especial. O simplemente es rodearse de lo más selecto $y$ predilecto que defina al individuo y que lo haga ser y connotar frente al resto del contexto funerario y por tanto de la población fúnebre que lo acompaña" (Benavente 1997: 45).

En todos los casos, ya sea desde una perspectiva del sentimiento, del acompañamiento, de lo material de la perpetuidad de la memoria, se busca materializar lo intangible, transformar el "artefacto material" en un "artefacto ideal" que subyace, radica en el trasfondo del pensamiento de los individuos. Es la expresión de la idea que debe de alguna manera transformarse en "cosa", ya que es ésta la que permanece, identifica y se mantiene en la memoria.

Aunque se alteren o cambien las relaciones entre los individuos, deudos y difuntos, varíen los objetos, sus formas y sus estilos, incluso se altere la organización social de la comunidad a la que pertenecen las "animitas", el sistema simbólico que las sustenta no se modifica. La muerte, su sentido, la ritualidad, el sentimiento hacia ella es permanente en el tiempo y pasa a formar parte de la historia de las comunidades.

\section{Como Baudrillard señala:}

"Las cosas se repliegan y se despliegan, desaparecen, entran en escena en el momento deseado. No cabe duda que estas innovaciones 


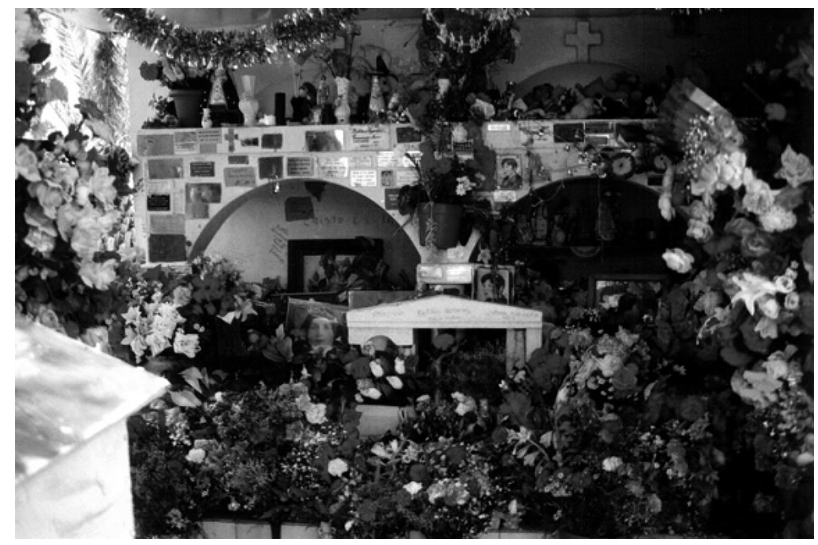

Figura 3. Animita "Las botitas negras". Cementerio Municipal de Calama. Fotografía de la autora, 2001.

no constituyen de ninguna manera una improvisación simple [...]" (2007: 15).

Es decir, tienen una intención y surgen de la libertad que tienen los individuos para elegir selectivamente aquellos elementos que "llaman" su sentido y determinan su sentimiento en los momentos dolorosos que provocan la pérdida de un ser cercano o querido. Es un sentimiento innato, y los sujetos necesitan de alguna manera expresar no solo sus sentimientos sino que también la cercanía que tuvieron con aquella persona a la cual perdieron en circunstancias trágicas. Pues las "animitas" no son otra cosa que una expresión simbólica que se manifiesta a través de una parafernalia consensuada de las pérdidas trágicas que sufren los individuos. Estas pérdidas ocurren de forma inesperada y en cualquier lugar; por esa razón, las encontramos en los lugares más inesperados, distribuyéndose a lo largo de todo el territorio.

Independientemente del significado que las "animitas" posean para el individuo y la comunidad, pragmáticamente se expresan en aquellas que son: 1) permanentes; 2) transitorias, y3) olvidadas.

Las primeras adquieren significación cuando el individuo recién a fallecido y los que albergan algún sentimiento por él manifiestan su pérdida a través de la elaboración de una obra constructiva nueva y reluciente, repleta de flores y ornamentos. El difunto recién ha partido de esta vida y, por lo mismo, existe la necesidad de engalanarlo y arroparlo simbólicamente.
La significación de transitoria acontece mediante el constante juego entre lo permanente y el olvido total hacia el difunto. Los deudos lo dejan de lado y solo lo recuerdan en ciertas fechas o momentos específicos. En este sentido, podríamos señalar que las "animitas" son una "obra viva" en permanente cambio, ya sea por el abandono o por el afán de los vivos de estar en comunicación con sus seres queridos conservándolos en su memoria. Esto último se mantiene mediante las visitas periódicas en que las flores y los ornamentos de las "animitas" son renovados.

El conjunto funerario entonces conduce a los deudos a mantener vigente la memoria por los seres queridos, en donde la obra constructiva surge del imaginario colectivo de familiares, amigos y conocidos. Ellos diseñan y generan una obra que es respaldada por el colectivo social a la que pertenece, de manera que tanto el difunto como los deudos son los verdaderos artífices de esta creación. Pero son estos últimos quienes a fin de cuentas ordenan el conjunto de procesos y elementos industriales, populares, comerciales y religiosos, de moda y de artesanías, todos de gran peso significativo, que permiten la conexión entre la identidad del difunto, el deudo y la memoria histórica, haciendo posible concretar la obra (Figura 3).

La significación que tiene la "animita" del olvido se traduce en la deconstrucción paulatina y definitiva de la obra. Es la pérdida de lo material, pero no solo eso se dilapida, sino que -y más importante- se disipa el interés por el difunto. Aquí son los deudos los que borran de su retina y sentimiento la memoria del muerto, contribu- 
yendo así a que la tradición histórica de las comunidades no se mantenga.

En apoyo a estos tres momentos que constituyen el contexto histórico de las "animitas", es importante señalar desde una perspectiva iconográfica, que la tipología de estas obras es muy variada, aunque como hemos esbozado a grandes líneas existen ciertos patrones fijos, definidos básicamente por la materialidad. Abundan los granitos, mármoles blancos y elegantes, calizas que imitan la grandeza y relevancia del mármol, negras andesitas, todos materiales que no son simples losas cubiertas de cemento o cal, convertidas en paredes y muros que albergarán el recuerdo del difunto para siempre, protegiéndolo tanto de las inclemencias atmosféricas como de peatones y vehículos.

Respecto a los diseños, destacan aquellos con líneas horizontales y verticales, trapezoidales en las formas enlazadas con la utilización de líneas onduladas y curvas, entre las que se insertan heterogéneos motivos y figuras. Estas últimas dependen del carácter del difunto, de su edad y su género. Generalmente se les acompañan de diversas imágenes y fotografías que suelen ser de temas religiosos, aunque el difunto no haya comulgado con esas creencias. Sin embargo debemos señalar que una gran proporción de estas casitas se construyen ajenas a cualquier tipo de creencia. Solamente reflejan y expresan el recuerdo terrenal que se tiene de los difuntos.

En su conjunto, las "animitas" se manifiestan como indudables viviendas para los muertos, con muros que permiten definirlas e identificarlas como perfectas casitas, moradas espirituales que albergan el recuerdo del difunto, de igual modo como sucede con las viviendas de los vivos.

\section{$\diamond$ Algunas consideraciones}

Realmente sabemos que las "animitas" tienen una significación permanente cuando, aunque el individuo haya recién fallecido, los que albergan algún sentimiento hacia él manifiestan la pérdida de su ser querido a través de una obra constructiva que implica la elaboración y construcción de una casita nueva y reluciente, llena de ornamentos alusivos a lo que el individuo fue en vida, con flores, estampitas y otros ornamentos. El difunto ha partido y la necesidad del amigo, del pariente, del conocido de adornarlo, visitarlo y cuidarlo es continua.

La significación transitoria se produce con lo cotidiano de la vida. Las personas recuerdan a sus difuntos en ocasiones puntuales, como las fiestas memoriales, debido a una rogativa, porque alguien pasó por el lugar y quiso dejar algo y acaso sin proponérselo, darle continuidad a la ritualidad que deben tener estos lugares. Es el constante juego entre lo permanente y el olvido total por el difunto. Los deudos lo dejan de lado y, por tanto, pareciera que los sentimientos por los muertos desaparecieran. En este sentido, podríamos señalar que las "animitas" son una "obra viva" en permanente cambio, ya sea por el abandono o por el afán de los vivos de estar en comunicación con sus seres queridos y guardarlos en su memoria. Esta memoria se mantiene viva solo por las visitas periódicas en que estos lugares son engalanados.

Señalamos que la significación que tiene la animita del olvido se traduce en la deconstrucción paulatina y permanente de la obra. Es la pérdida total del sentimiento de los individuos que se manifiesta materialmente. Podríamos incluso decir que al perderse lo más relevante que el individuo posee -sus sentimientos-, ya no importa lo material, ejemplificado con estas casitas. Se ha perdido el interés por recordar al ser querido, se olvidan las identidades y, por lo tanto, no se mantienen las tradiciones. Aquí son los deudos los que borran de su retina la materialidad y, con esto, la memoria, contribuyendo de esta forma a que la historia e identidad de las comunidades no se mantengan.

Finalmente, debemos tener presente que en las "animitas" el sentido que se le otorga al alma de las personas y su expresión visual es posible extenderlo al sentimiento sobre la memoria de los difuntos. Como señala Thomas (1983: 521), "se convierte en un esfuerzo de una presentación real o simbólica del desaparecido".

La lápida es el primer elemento necesario que debe especificar con detalle la identidad del difunto $-y$ si bien las "animitas" muchas veces son inidentificables-, aparece como una luz que ilumina mediante una multiplicidad de elementos que escapan a la función inicial de identificar, pero que efectivamente aportan de una manera ornamental a mantener la memoria del difunto. 
En el ámbito de la muerte, memoria e identidad son conceptos íntimamente unidos que funcionan como vínculos, que conservan la tradición histórica de la sociedad, y las "animitas" son un pequeño vehículo para que esto suceda.

La memoria mediante el recuerdo y la identidad se hace presente en la asignación de signos específicos pragmáticos que señalan simplemente los datos del difunto. Éstos adquieren una connotación simbólica en el tiempo histórico, en la medida que la sociedad se la otorgue. Y como observamos previamente, se les asigna poder simbólico cuando la significación de la "animita" es permanente y no llega a la etapa del olvido. Muchas veces esta significación es postergada por los propios deudos al abandonar de modo momentáneo el recuerdo de su difunto, sufriendo una transición que puede tener dos fines, el reciclaje a la significación permanente o a la deconstrucción total, culminando con el olvido de la "animita" y del difunto.

Ambos aspectos - memoria e identidad-, por pertenecer a la cultura y a la tradición, se expresan mediante signos, los que pasan a ser símbolos en la medida que las sociedades los integran, formando parte de sus contextos históricos tradicionales y, por lo tanto, traspasan el ámbito de la funebria.

Según un informante anónimo (2007):

"No son el casamentero San Antonio, el pescador San Pedro ni la protectora de las causas imposibles, Santa Rita de Casia. Tampoco, Fray Andresito, el príncipe de los mendigos, tan admirado por los guachacas. ${ }^{2}$ Las animitas son todos los otros finados a

\footnotetext{
2 Término popular y despectivo usado para referirse a personas de baja extracción social.
}

quienes los chilenos les piden favores; personas de vidas anónimas que sufrieron una muerte violenta y especialmente injusta, lo que las hacen merecedoras de esas casitas tan guachacas, las grutas.

"Las animitas están en todas partes; no hay en Chile una ciudad donde falten; y iay! de los vecinos si es que no reponen las floreso dejan que se consuman todas las velas, porque la tradición popular recuerda a los occisos con cariño. Pero lo que aflora frente a las animitas no es ternura ni compasión. Es la seguridad de que estamos ante un muerto bueno, un alma blanca. Veamos qué nos dice la teoría eclesiástica respecto de esta fe.

Don Antonio Bentué, teólogo con una chorrera de títulos y profe de la Ponti cuica, explica: 'Las animitas son una mezcla, un sincretismo, que toma de España el culto a la Virgen del Carmen, a la que se le puede pedir favores, y que toma del mundo indígena el culto a los antepasados y la idea de que los muertos se quedan cerca nuestro, tal como los mapuches creen que sus ancianos están en las nubes, protegiéndolos".

En síntesis, las "animitas" que encontramos en calles, vías, jardines, plazas, desiertos, playas y condominios recorren y caracterizan nuestro territorio, todos los momentos de nuestra historia, desde la opulencia de algunos, el olvido de otros, las creencias de unos o lo agnóstico de otros.

Son permanentes en nuestras vidas en la medida que recordemos a nuestros difuntos, y transitorias en nuestro quehacer tal como cualquier ritual, el que se cumple cuando nos acordamos de fechas o momentos especiales; finalmente son olvidadas en la medida que las marginamos de nuestras vidas totalmente; pero que a fin de cuentas son parte de la identidad y también de nuestra memoria histórica.

\section{* Referencias citadas}

ARIÉS, P., 1983. El hombre ante la muerte. Taurus, Madrid.

BAUDRILLARD, J., 2007. El sistema de los objetos. Siglo XXI, Madrid.
BENAVENTE, A., 1997. Las vanidades en la iconografía funeraria chilena. Anales de la Universidad de Chile (6 $6^{\text {a }}$ serie) 6: 41-47.

THOMAS, V., 1983. Antropología de la muerte. Fondo de Cultura Económica, México D.F. 


\section{ESTUdiOS ATACAMEÑOS \\ ARquEOLOGÍA Y ANTROPOLOGÍA SURANDINAS}

\section{NORMAS EDITORIALES}

\section{Generalidades}

1. Enviar el manuscrito escrito en programa Word, y un CD o DVD con copia impresa en papel a nombre de:

Editora Estudios Atacameños, Arqueología y Antropología Surandinas

Instituto de Investigaciones Arqueológicas y Museo de la Universidad Católica del Norte

Gustavo Le Paige 380

San Pedro de Atacama

1410000 - CHILE

Email:eatacam@ucn.cl

El texto deberá estar escrito en español, en letra Times New Roman tamaño 12, estilo Normal.

2. El escrito, considerando todas las secciones e incluyendo bibliografía y anexos, no deberá sobrepasar las 30 páginas tamaño carta, a espacio simple y márgenes de $2,5 \mathrm{~cm}$.

3. Es responsabilidad de los autores atenerse a estas normas, pulir la redacción, revisar la ortografía y proporcionar imágenes claras en buena resolución.

\section{Normativas básicas}

\section{Secciones del manuscrito:}

Resumen en español (5 a 10 líneas)

Palabras claves

Abstract en inglés (5 a 10 líneas)

Key words
Texto

Agradecimientos

Referencias citadas

Anexos

Lista y leyenda de figuras y tablas.

2. Título del trabajo: Letra Times New Roman tamaño 12, mayúscula, centrado.

3. Autores: El nombre o nombres deberá(n) alinearse en el margen izquierdo, indicándose en notas numeradas al pie de página institución, dirección postal y dirección electrónica.

4. Texto: Podrá desarrollarse en segmentos que, según la inclusión de unos en otros, irán designados con títulos primarios, secundarios y terciarios.

Los títulos primarios deberán ser escritos en letra mayúscula, normal y alineados a la izquierda.

Los títulos secundarios deberán ser escritos en letra minúscula, negrita y alineados a la izquierda.

Los títulos terciarios deberán ubicarse al inicio del párrafo correspondiente, en cursiva y separados del texto por un punto seguido.

Los títulos de Resumen y Abstract deberán ir en minúsculas y en negrita.

Los párrafos no deberán tener sangría y deberán estar separados unos de otros por un interlineado. 
5. Notas al pie de página: Todas las notas deberán ir al pie de página y numeradas correlativamente en números arábigos $(1,2,3 \ldots)$ en superíndice, continuando la secuencia iniciada por los datos de los autores.

6. Tablas: Todas las tablas deberán ser enviadas en escala de grises y numeradas en el orden en que son mencionadas en el texto. Se deberá proveer un título corto para cada tabla y gráfico, en letra minúscula.

7. Figuras (fotografías, mapas, dibujos, gráficos): Deberán ser numeradas secuencialmente en el mismo orden en que son citadas en el texto y ceñirse a las mismas especificaciones que las tablas. Las imágenes deben ser enviadas en escala de grises en archivos separados del texto, en formato TIFF o JPG con una resolución de al menos $300 \mathrm{dpi}$.

8. Bibliografía: Las referencias citadas deberán ser dispuestas en el siguiente orden: autor(es), año, título, imprenta, lugar de publicación. Los autores deberán ir en mayúscula. Solo la primera letra del título deberá ir en mayúscula. El título de revista, libro o monografía deberá aparecer en cursiva. Se deberá consignar solamente las iniciales de los nombres de los autores; cuando haya más de un autor, solamente para el primero deberá aparecer el apellido antes que el nombre. Todos los artículos de revista deben llevar el número de páginas. Todas las referencias deben ir separadas por un espacio.

\section{Cita de libro:}

HAMPTON, D. R., C. E. SUMMER y R. A. WEBER, 1978. Organizational behavior and the practice of management. Editorial Scott Foresman, Glenview, Illinois.

\section{Cita de revista:}

MUNIZAGA, J., 1974. Deformación craneal y momificación en Chile. Anales de Antropología 11:329-336.

\section{Cita de artículo en un libro:}

NICHOLS, D. L., 1987. Prehispanic irrigation at Teotiahuacán, new evidence: The Tlajinga canals. En Teotiahuacán: Nuevos datos, nuevas síntesis, nuevos problemas, E. McClung de Tapia y E. C. Rattray (Eds.), pp. 133-16o. Universidad Autónoma de México, México D. F.

\section{Cita de artículo en un volumen de una serie:}

KHOL, P. L., 1987. The use and abuse of world systems theory: The case of the Pristine West Asian State. En Advances of archaeological method and theory vol. 11, M. Schiffer (Ed.), pp. 1-35. Academic Press, San Diego. 